\title{
Evaluation of basic motor competencies in primary school in Luxembourg
}

\author{
Claude Scheuer, Andreas Bund, Sandra Heck et Christian Herrmann
}

Claude Scheuer.

Andreas Bund.

Sandra Heck.

Christian Herrmann.

Résumé. An objective of physical education (PE) is supporting students' positive motor development. Therefore, it is indispensable for them to be in command of the necessary basic motor competencies (in German: Motorische Basiskompetenzen; МОВАК) as the prerequisites to be able to participate in the culture of human movement. For the implementation of the MOBAK approach in Luxembourg (MOBAK-LUX), we developed the test instruments MOBAK-LUX-PS for preschoolers, MOBAK-LUX-1 for first graders, MOBAK-LUX-3 for third graders and MOBAK-LUX-5 for fifth graders. These motor tests are conducted on a voluntary basis by interested schools and teachers at the beginning of each school year. In general, about one third of students in the different class levels have support needs in at least one area of basic motor competence. The support needs are prevalent mostly in the area object control and girls generally have lower results than boys, especially in object control.

Mots-clés. Basic motor competencies, Pedagogical diagnosis, Educational monitoring, Support needs

\section{Introduction}

One major objective of physical education (PE) as a school subject is supporting students' positive motor development and physical literacy. Therefore, it is indispensable for them to be in command of the necessary basic motor competencies (in German: Motorische Basiskompetenzen; MOBAK) to be able to participate in the culture of human movement, play and sports in the sense of cultural participation (Herrmann et al., 2015). When it comes to the assessment and monitoring of respective motor competencies, the existence of suitable test instruments has gained increasingly relevance in relation to the implementation of standards in educational systems. Given that the topic of test tasks is of primordial importance for teachers in relation to their diagnostic competence, adequate test instruments disposing of curricular validity are necessary as a prerequisite for educational testing (Heck \& Scheuer, 2019). Such test instruments should help teachers gain more relevant information about students' competencies and determine their respective motor competence profile, in order to support them on the way to more individualized learning. Furthermore, the corresponding test instruments can be implemented within the framework of educational monitoring, with the objective of making students' performance scores comparable between schools, regions or student groups, as well as to identify potential risk populations with low motor competencies on a regional or national level.

In previous studies, the MOBAK approach to assess basic motor competencies has been identified as appropriate to follow in developing corresponding test instruments for different age respectively grade levels (e.g. Herrmann et al., 2015; Scheuer, Herrmann, \& Bund, 2019).

In this sense, basic motor competencies, defined as a prerequisite for active participation in the culture of movement, play, and sports, express a level of minimal requirements in the form of minimum standards. They are operationalized as observable performances of movement-related activities that we refer to as basic motor qualifications formulated as can-do statements (like e.g. "can balance", "can throw" or "can catch") to be achieved by all students of a certain age level in a certain cultural context. Basic motor qualifications are context-specific and oriented towards functionality and respective test items (like e.g. balancing over a bench, performing a forward roll on a flat mat or catching a ball thrown against a wall), assess the mastery of motor skills in predefined situations, in opposition to other motor test 
concepts based on motor abilities or motor skills (Scheuer, Herrmann, \& Bund, 2019). Thus, basic motor competencies are (1) dispositions or latent constructs; (2) not measured directly, but recorded by the presence of basic motor qualifications; (3) product-oriented in the form of the successful solution of a given problem situation; and (4) based on the expected learning outcomes as formulated in the curriculum (Herrmann et al., 2015).

For the purpose of pedagogical diagnosis (identification of students with low or high basic motor competencies) and educational monitoring (identification of risk populations with low basic motor competence levels and quality management by feedback to the school system on the school and system level), we designed and validated test instruments for assessing the basic motor competencies of primary school students in Luxembourg: MOBAK-LUX-PS (Scheuer, 2018a) for preschoolers; MOBAK-LUX-1 (Scheuer, 2016a) for first graders; MOBAK-LUX-3 (Scheuer, 2016b) for third graders; and MOBAK-LUX-5 (Scheuer, 2018b) for fifth graders. In cooperation with the Luxembourgish Ministry of Education, these motor test series are conducted on a voluntary basis by interested schools and teachers at the beginning of each school year.

In the following, the implementation of MOBAK-LUX in Luxembourg and selected results of the testing in recent years will be presented.

\section{Methods}

\section{The MOBAK-LUX test instruments}

All four test instruments consist of items in the four test dimensions "locomotion", "object control", "moving in water" and "object locomotion" (MOBAK-LUX-PS: 15 test items; MOBAK-LUX-1: 16 test items; MOBAK-LUX-3: 16 test items; MOBAK-LUX-5: 15 test items; table 1). The final composition of each test instrument results from a much larger selection of possible test items that were developed and discussed in the context of several expert discussions on the basis of normative pedagogical considerations. This process of developing the test items in line with curricular circumstances, related in our case to the minimum standards for PE in primary school in Luxembourg, may be understood as a design step helping to maintain curricular validity and content validity. As these standards include general competencies and qualifications that are also embedded in other curricula, we are confident that the MOBAKLUX test instruments possess a high content validity for the curricula of other countries as well.

In our case, the MOBAK-LUX item pools used as measurement tools were defined on two levels: mastery of Level 1 as a minimum standard which should be achieved by all students, and mastery of Level 2 as an advanced level, including additional difficulty in the form of a more complex task or the execution of the task under more difficult conditions (Scheuer, Bund, \& Herrmann, 2019). Students who do not pass Level 1 of a MOBAK-LUX test task have deficiencies in the respective basic motor qualification. Thus, a MOBAK-LUX test item is ordinally scaled $(0,1$ and 2$)$. 
Actes de la 11ème Biennale de l'ARIS : Former des citoyens physiquement éduqués. Axe 2 - Vers une éducation physique de qualité, 10.25518/sepaps20.323

Table 1: Overview of the MOBAK-LUX test instruments and test items

\begin{tabular}{|c|c|c|c|c|}
\hline Competence area & MOBAK-LUX-PS & MOBAK-LUX-1 & MOBAK-LUX-3 & MOBAK-LUX-5 \\
\hline \multirow[t]{5}{*}{ Locomotion } & Balancing & Balancing & Balancing & Balancing \\
\hline & Rolling & Rolling & Rolling & Rolling \\
\hline & Stabilizing & Stabilizing & Stabilizing & Stabilizing \\
\hline & Running & Running & Running & Running \\
\hline & Jumping & Jumping & Jumping & Jumping \\
\hline \multirow[t]{6}{*}{ Object control } & Throwing & Throwing & Throwing and catching & Throwing and catching \\
\hline & Catching & Catching & & \\
\hline & Bouncing & Bouncing & Bouncing & \\
\hline & Dribbling & Dribbling & Dribbling & Dribbling \\
\hline & & Controlling with a stick & Controlling with a stick & Controlling with a stick \\
\hline & & & Hitting a target & Hitting a target \\
\hline \multirow[t]{3}{*}{ Object locomotion } & Changing track & Changing track & Changing track & Changing track \\
\hline & Braking and stopping & Braking and stopping & Braking and stopping & Braking and stopping \\
\hline & Slalom riding & Slalom riding & Slalom riding & Slalom riding \\
\hline \multirow[t]{3}{*}{ Moving in water } & Moving & Moving & Gliding & Swimming \\
\hline & Diving & Diving & Diving & Diving \\
\hline & Floating & Floating & Floating & Floating \\
\hline
\end{tabular}

\section{Support needs in basic motor competencies}

Students who are not in command of certain basic motor qualifications in a certain domain of basic motor competence (e.g. "locomotion", "object-control") are deficient in this domain and thus might encounter difficulties as they progress through school. Moreover, their participation in the sports, play, and movement culture in society is potentially in danger. In order to identify respective students, the following definition of low basic motor competence based on a normative approach is applied:

1. Students who pass less than two thirds of the Level 1 tasks in a test/competence area, have not achieved the minimal requirements and support is needed. Thus, they should practice specifically in this competence area ; 
2. Students who pass at least two thirds of the Level 1 tasks in a test/competence area, have achieved the minimal requirements and we assume that they have the basic requirements for participation in this competence area ;

3. Students who pass at least two thirds of the Level 2 tasks in a test/competence area, have exceeded the minimal requirements and we assume that they have reached advanced requirements for participation in this competence area.

\section{Results and discussion}

In the following, a selection of results of the MOBAK-LUX surveys implemented in recent years will be presented. The focus lies on results from the testing of first and third graders, as the respective test instruments were developed first, leading to more available data for these grades. In general, the results of the 2018 surveys indicate that a considerable proportion of students in all tested grades showed low basic motor competence levels in at least one of the four competence areas. Passing less than two thirds of the basic test items in at least one area, these students show respective support needs: $41.8 \%$ of pre-schoolers $(\mathrm{N}=570), 48.4 \%$ of first graders $(\mathrm{N}=364), 24.5 \%$ of third graders $(\mathrm{N}=437)$ and $22.0 \%$ of fifth graders $(\mathrm{N}=486)$.

When looking at the third grade, where MOBAK-LUX was implemented first, the results of the surveys between 2015 and 2018 indicate low basic motor competences in at least one of the four competence areas for approximately a quarter (24.5\%) up to a third (31.8\%) of the participating students (table 2). The results of 2017 show that in general, similar to other studies based on the MOBAK concept (Herrmann, Gerlach, \& Seelig, 2015; Herrmann \& Seelig, 2017), girls have more frequently low basic motor competencies than boys (38.2\% vs. 26.5), especially in "object control" (34.0\% vs. $19.3 \%$; table 3$)$.

Looking at the results in first grade between 2016 and 2018 (MOBAK-LUX-1), the incidence of support needs in at least one of the four competence areas is even higher: 31.3-48.4\%. In 2017, the differences between girls and boys when it comes to the general results (44.4\% vs. $34.3 \%$ ) and the "object control" results respectively (34.9\% vs. $21.7 \%$ ) are very similar to those in grade three.

In summary, the following results can be observed: about one third of students in the different class levels have support needs in at least one area of basic motor competence; these support needs are prevalent mostly in the competence area "object control"; girls generally have lower results than boys, especially in the competence area "object control". These results are in line with those of other studies based on the MOBAK concept (Herrmann, Gerlach, \& Seelig, 2015; Herrmann \& Seelig, 2017). Recent results in preschool (MOBAK-LUX-PS) and fifth grade (MOBAK-LUX-5) confirm these tendencies.

Table 2: MOBAK-LUX-3 general results 2015-2018 (in \%) 
Actes de la 11ème Biennale de l'ARIS : Former des citoyens physiquement éduqués. Axe 2 - Vers une éducation physique de qualité, 10.25518/sepaps20.323

\begin{tabular}{|c|c|c|c|c|c|}
\hline Competence area & Year & $\begin{array}{l}\text { Support } \\
\text { needs }\end{array}$ & Minimal requirements & Advanced requirements & $\mathrm{N}$ \\
\hline \multirow[t]{4}{*}{ Locomotion } & 2015 & 5.3 & 23.1 & 71.6 & 468 \\
\hline & 2016 & 7.4 & 25.8 & 66.8 & 446 \\
\hline & 2017 & 5.7 & 30.4 & 64.0 & 566 \\
\hline & 2018 & 8.1 & 30.9 & 61.0 & 431 \\
\hline \multirow[t]{4}{*}{ Object control } & 2015 & 19.6 & 38.8 & 41.6 & 449 \\
\hline & 2016 & 23.2 & 32.9 & 43.9 & 410 \\
\hline & 2017 & 25.8 & 51.3 & 22.9 & 546 \\
\hline & 2018 & 19.6 & 42.9 & 37.5 & 357 \\
\hline \multirow[t]{4}{*}{ Object locomotion } & 2015 & 5.7 & 25.7 & 68.8 & 405 \\
\hline & 2016 & 3.7 & 16.7 & 79.6 & 348 \\
\hline & 2017 & 2.9 & 26.3 & 70.7 & 482 \\
\hline & 2018 & 0.3 & 15.3 & 84.4 & 353 \\
\hline \multirow[t]{4}{*}{ Moving in water } & 2015 & 7.9 & 31.2 & 61.0 & 420 \\
\hline & 2016 & 13.3 & 33.7 & 53.1 & 377 \\
\hline & 2017 & 11.4 & 28.0 & 60.6 & 457 \\
\hline & 2018 & 8.0 & 28.0 & 64.0 & 289 \\
\hline \multirow[t]{4}{*}{ MOBAK-Total } & 2015 & 29.5 & 70.5 & / & 448 \\
\hline & 2016 & 31.1 & 68.9 & / & 473 \\
\hline & 2017 & 31.8 & 68.2 & / & 583 \\
\hline & 2018 & 24.5 & 46.2 & 29.3 & 437 \\
\hline
\end{tabular}


Evaluation of basic motor competencies in primary school in Luxembourg

Table 3: MOBAK-LUX-3 general results 2017 (in \%)

\begin{tabular}{|c|c|c|c|c|c|}
\hline Competence area & Sex & $\begin{array}{l}\text { Support } \\
\text { needs }\end{array}$ & Minimal requirements & Advanced requirements & $\mathrm{N}$ \\
\hline \multirow[t]{3}{*}{ Locomotion } & all & 5.7 & 30.4 & 64.0 & 564 \\
\hline & boys & 6.3 & 31.4 & 62.2 & 315 \\
\hline & girls & 4.8 & 28.9 & 66.3 & 249 \\
\hline \multirow[t]{3}{*}{ Object control } & all & 25.7 & 51.3 & 23.0 & 544 \\
\hline & boys & 19.3 & 50.3 & 30.4 & 306 \\
\hline & girls & 34.0 & 52.5 & 13.4 & 238 \\
\hline \multirow[t]{3}{*}{ Object locomotion } & all & 2.9 & 26.4 & 70.7 & 481 \\
\hline & boys & 3.3 & 26.8 & 69.9 & 269 \\
\hline & girls & 2.4 & 25.9 & 71.7 & 212 \\
\hline \multirow[t]{3}{*}{ Moving in water } & all & 11.4 & 28.1 & 60.5 & 456 \\
\hline & boys & 11.2 & 30.5 & 58.3 & 259 \\
\hline & girls & 11.7 & 24.9 & 63.5 & 197 \\
\hline \multirow[t]{3}{*}{ MOBAK-Total } & all & 31.7 & 68.3 & / & 583 \\
\hline & boys & 26.5 & 73.5 & / & 324 \\
\hline & girls & 38.2 & 61.8 & / & 259 \\
\hline
\end{tabular}

\section{Conclusion}

In recent years, many school classes in Luxembourg have participated on a voluntary base in the MOBAK-LUX surveys. The increasing interest shows that the implementation of competence-oriented test tasks has found acceptance amongst teachers and helps them to identify students with support needs in certain areas of motor competence. Accordingly, the annual MOBAK-LUX testing will be linked in the future as an additional, optional module to the national educational monitoring surveys existing for mathematics, German, and French languages, undertaken by the Luxembourgish Centre for Educational Testing (LUCET) of the University of Luxembourg. Furthermore, a MOBAK support framework based on support measures on school and classroom level for students with different motor competence levels has been developed by the University of Luxembourg and is currently being implemented by the Luxembourgish Ministry of Education on a national level. 
Actes de la 11ème Biennale de l'ARIS : Former des citoyens physiquement éduqués. Axe 2 - Vers une éducation physique de qualité, 10.25518/sepaps20.323

\section{Bibliographie}

Heck, S., \& Scheuer, C. (2019). Diagnostic Competence of Physical Education Teachers. In M. A. Peters (ed.), Encyclopedia of Teacher Education. Singapore: Springer Singapore

Herrmann, C., Bund, A., Gerlach, E., Kurz, D., Lindemann, U., Rethorst, S., ... \& Pühse, U. (2015). A review of the assessment of basic motor qualifications and competencies in school. International Journal of Physical Education, 52(3), 2-13.

Herrmann, C., Gerlach, E., \& Seelig, H. (2015). Development and validation of a test instrument for the assessment of basic motor competencies in primary school. Measurement in Physical Education and Exercise Science, 19(2), 80-90. http://doi.org/10.1080/1091367X.2014.998821

Herrmann, C., \& Seelig, H. (2017). Structure and profiles of basic motor competencies in the third grade-validation of the test instrument MOBAK-3. Perceptual and Motor Skills, 124(1), 5-20. http://doi.org/10.1177/0031512516679060

Scheuer, C. (2016a). MOBAK-LUX-1 Testmanual. Luxembourg: SCRIPT; University of Luxembourg: Retrieved from https://www.researchgate.net/publication/324151926 MOBAK-LUX-1 Testmanual

Scheuer, C. (2016b). MOBAK-LUX-3 Testmanual. Luxembourg: SCRIPT; University of Luxembourg. Retrieved from https://www.researchgate.net/publication/324152031_MOBAK-LUX-3 Testmanual

Scheuer, C. (2018a). MOBAK-LUX-PS Testmanual. Luxembourg: SCRIPT; University of Luxembourg. Retrieved from https://www.researchgate.net/publication/332409612 MOBAK-LUX-PS Testmanual

Scheuer, C. (2018b). MOBAK-LUX-5 Testmanual. Luxembourg: SCRIPT; University of Luxembourg. https://www.researchgate.net/publication/332409613_MOBAK-LUX-5 Testmanual

Scheuer, C., Bund, A., \& Herrmann, C. (2019). Diagnosis and Monitoring of Basic Motor Competencies among ThirdGraders in Luxembourg. An Assessment Tool for Teachers. Measurement in Physical Education and Exercise Science, 23(3), 258-271. http://doi.org/10.1080/1091367X.2019.1613998

Scheuer, C., Herrmann, C., \& Bund, A. (2019). Motor tests for primary school aged children: A systematic review. Journal of Sports Sciences, 37(10), 1097-1112. http://doi.org/10.1080/02640414.2018.1544535

PDF automatiquement généré le 2023-04-26 12:53:35

Url de l'article : https://popups.uliege.be/sepaps20/index.php?id=323

Publié par ULiège Library en Open Access et distribué suivant les termes et les conditions de la licence CC-BY (https://creativecommons.org/licenses/by/4.0/deed.fr) 